Rev. Biol. Neotrop. 6(1):55-73, 2009

\title{
ENOLOGIA REPRODUTIVA E BIOMETRIA DE FRUTOS E SEMENTES DE três espécies de Byrsonima Rich. ex Kunth (Malpighiaceae) no Parque do Bacaba, Nova Xavantina - Mato Grosso
}

\author{
Divino Vicente Silvério \\ Programa de Pós-Graduação em Ecologia e Conservação, Universidade do Estado de Mato \\ Grosso (UNEMAT), Campus Universitário de Nova Xavantina, BR 158 km 148, Caixa Postal 8, \\ Nova Xavantina, 78690-000, Mato Grosso, Brasil; e-mail: vicentth@yahoo.com.br

\section{Clarissa Fernandes-Bulhão} \\ Departamento de Biologia, Universidade do Estado de Mato Grosso (UNEMAT), Campus \\ Universitário de Nova Xavantina, BR 158 km 148, Caixa Postal 8, Nova Xavantina, 78690-000, \\ Mato Grosso, Brasil; e-mail: clarissafernandesb@yahoo.com.br
}

\begin{abstract}
Resumo: Este trabalho teve como objetivo estudar a fenologia reprodutiva e a biometria de frutos e sementes de Byrsonima verbascifolia, $B$. crassa e $B$. orbignyana, espécies ocorrentes no Parque do Bacaba, em Nova Xavantina, Mato Grosso, visando auxiliar no planejamento de extração e comercialização dos frutos. As observações fenológicas foram realizadas entre maio de 2006 e abril de 2007. Foram avaliadas as características biométricas de 200 frutos de cada espécie. A floração ocorre durante a estação seca e no início das chuvas. A frutificação está associada aos períodos de maior precipitação na região e a dispersão durou aproximadamente três meses para cada espécie. Os pesos médios dos frutos de $B$. crassa, $B$. orbignyana e $B$. verbascifolia foram, respectivamente: $0,30 \pm 0,05 \mathrm{~g}, 2,41 \pm 0,51 \mathrm{~g}$ e $3,81 \pm 1,99 \mathrm{~g}$. A polpa contribuiu com $67,79 \%, 84,38 \%$ e $88,11 \%$ do peso total do fruto de $B$. crassa, $B$. orbignyana e $B$. verbascifolia, respectivamente. As espécies apresentaram tendência para frutos achatados e endocarpos compridos. $B$. verbascifolia e $B$. orbignyana se mostraram mais adequadas para comercialização por apresentar os maiores frutos e o maior rendimento de polpa. Entretanto, deve haver manejo racional e sustentável das áreas exploradas para que a coleta dos frutos não cause erosão genética das espécies.
\end{abstract}

Palavras-chave: Byrsonima, biometria, frutos.

Reproductive phenology and biometry of fruits and Seeds of three species of Byrsonima Rich. EX Kunth (Malpighiaceae) in Bacaba Park, Nova Xavantina - Mato Grosso

AвSTRACT: The purpose of this work was to study the reproductive phenology and biometry of Byrsonima verbascifolia, B. crassa, and B. orbignyana fruits and seeds, species that occur in Bacaba Park, Nova Xavantina, Mato Grosso, in order to plan the fruit extraction and trading. The phenological observations were carried out from May 2006 to April 2007. We assessed the biometric characteristics of 200 fruits of each species. Flowering occurs during the dry season and in the beginning of the rainy season. The fruits are associated with high precipitation periods in that area, and dispersion lasted approximately three months for each species. B. crassa, B. orbignyana, and B. verbascifolia average fruit weight was, respectively: $0.30 \pm 0.05 \mathrm{~g}, 2.41 \pm 0.51 \mathrm{~g}$ and $3.81 \pm 1.99 \mathrm{~g}$. The pulp contributed with $67.79 \%, 84.38 \%$, and $88.11 \%$ of $B$. crassa, $B$. orbignyana, and $B$. verbascifolia total fruit weight, respectively. These species presented a trend to flattened fruits and long endocarp. $B$. verbascifolia and $B$. orbignyana proved to be more appopriate for trading since they presented the biggest fruits and the highest pulp yield. However, there should be a rational and sustainable management of the areas so that the fruit collection does not provoke genetic erosion of these species.

KeY wORDs: Byrsonima, biometry, fruits. 


\section{INTRODUÇÃO}

$\mathrm{O}$ gênero Byrsonima Rich. ex Kunth, cujas espécies são popularmente conhecidas como "murici", tem aproximadamente 150 espécies nas regiões neotropicais (Joly, 2002; Vicentini \& Anderson, 1999). Muitas dessas são amplamente utilizadas em medicina popular (Cardoso, 2006; Gusmão et al., 2006; Pott et al., 2004; Sannomiya et al., 2005). Além disso, diversos estudos têm revelado que algumas espécies de murici apresentam vários compostos químicos importantes com potencial para uso em diferentes áreas (Cardoso, 2006; Figueiredo et al., 2005; Gil et al., 2005; Mendanha et al., 2008; Mendes et al., 1999; Rezende \& Fraga, 2003; Sannomiya et al., 2005). Os frutos possuem alto valor nutricional (Brasil, 2002; Guimarães \& Silva, 2008) e nas regiões de ocorrência são intensamente consumidos in natura ou na forma de sucos, licores, geleias, doces e sorvetes (Almeida et al., 1998, 2008; Figueiredo et al., 2005). As populações locais que vivem do extrativismo têm no murici uma de suas principais fontes de renda (IBGE, 2006), sendo comum sua comercialização em feiras livres (Gusmão et al., 2006).

Estudos acerca da fenologia reprodutiva e a caracterização biométrica de frutos e sementes são frequentes em trabalhos com espécies que apresentam potencial para a comercialização (Botezelli et al., 2000; Cruz et al., 2001; Cruz \& Carvalho, 2002; Falcão \& Clement, 2000; Gusmão et al., 2006; Morellato, 1995; Oliveira, 2008). O conhecimento sobre a fenologia reprodutiva permite avaliar a disponibilidade de frutos ao longo do ano (Morellato, 1995), bem como a relação entre os eventos fenológicos e as mudanças no meio biótico e abiótico (Morellato et al., 1990). A biometria de frutos constitui importante instrumento para detectar a variabilidade fenotípica nas populações, fornecendo informações úteis para as iniciativas de seleção e melhoramento genético (Cruz \& Carvalho, 2002; Gusmão et al., 2006; Moraes \& Alves, 2002).

A rápida expansão agrícola sobre o Cerrado tem desprezado o uso potencial das espécies nativas (Klink \& Machado 2005; Machado et al., 2004). Embora algumas espécies frutíferas deste bioma já façam parte da alimenta- ção humana, como os muricis, são necessárias mais pesquisas para que possam ingressar definitivamente no mercado formal de frutas (Cavalcante et al., 2009).

Neste contexto, no presente estudo buscou-se caracterizar o comportamento fenológico reprodutivo e a biometria dos frutos e sementes de três espécies de Byrsonima (murici), visando auxiliar no planejamento da extração e comercialização dos frutos.

\section{Material e métodos}

\section{ÁREA DE ESTUDO}

OParque do Bacaba (1441'09"S,52 20'09"W) é uma unidade de conservação municipal com cerca de 470 hectares, localizada no município de Nova Xavantina, Mato Grosso, no leste matogrossense. O parque está inserido no domínio do bioma Cerrado e apresenta várias de suas fitofisionomias; a vegetação predominante é o cerrado stricto sensu, que está em contato com áreas florestais e manchas de cerradão. No Parque do Bacaba, a família Malpighiaceae está representada por oito gêneros e 25 espécies (Freitas, comunicação pessoal).

De acordo com os dados coletados na Estação Metereológica da Universidade de Mato Grosso (UNEMAT), durante o período deste estudo (maio de 2006 a abril de 2007), o clima apresentou duas estações bem definidas: uma seca, de abril a agosto, e uma chuvosa, de setembro a março (Figura 1). Em abril de 2007, a precipitação foi muito pequena, de apenas $8,7 \mathrm{~mm}$ e, portanto, este mês foi considerado como parte da estação seca. A precipitação anual foi de $1.442 \mathrm{~mm}$, estando em torno da média anual para a região (Silva et al., 2008). A temperatura média variou entre $21^{\circ} \mathrm{C}$ em junho e $26^{\circ} \mathrm{C}$ em setembro, com média anual de $24{ }^{\circ} \mathrm{C}$ (Figura 1). Segundo Silva et al. (2008), este padrão climático corresponde ao tipo Aw de Köppen, também chamado Tropical Úmido ou Tropical de Savana.

\section{ESPÉCIES ESTUDADAS}

As espécies estudadas foram Byrsonima verbascifolia (L.)DC., B. orbignyana A.Juss. e B. crassa Nied. São plantas de porte arbóreo, com inflorescências em racemos simples axilares e frutos tipo drupa globosa, em cachos pendentes (Joly, 2002). 


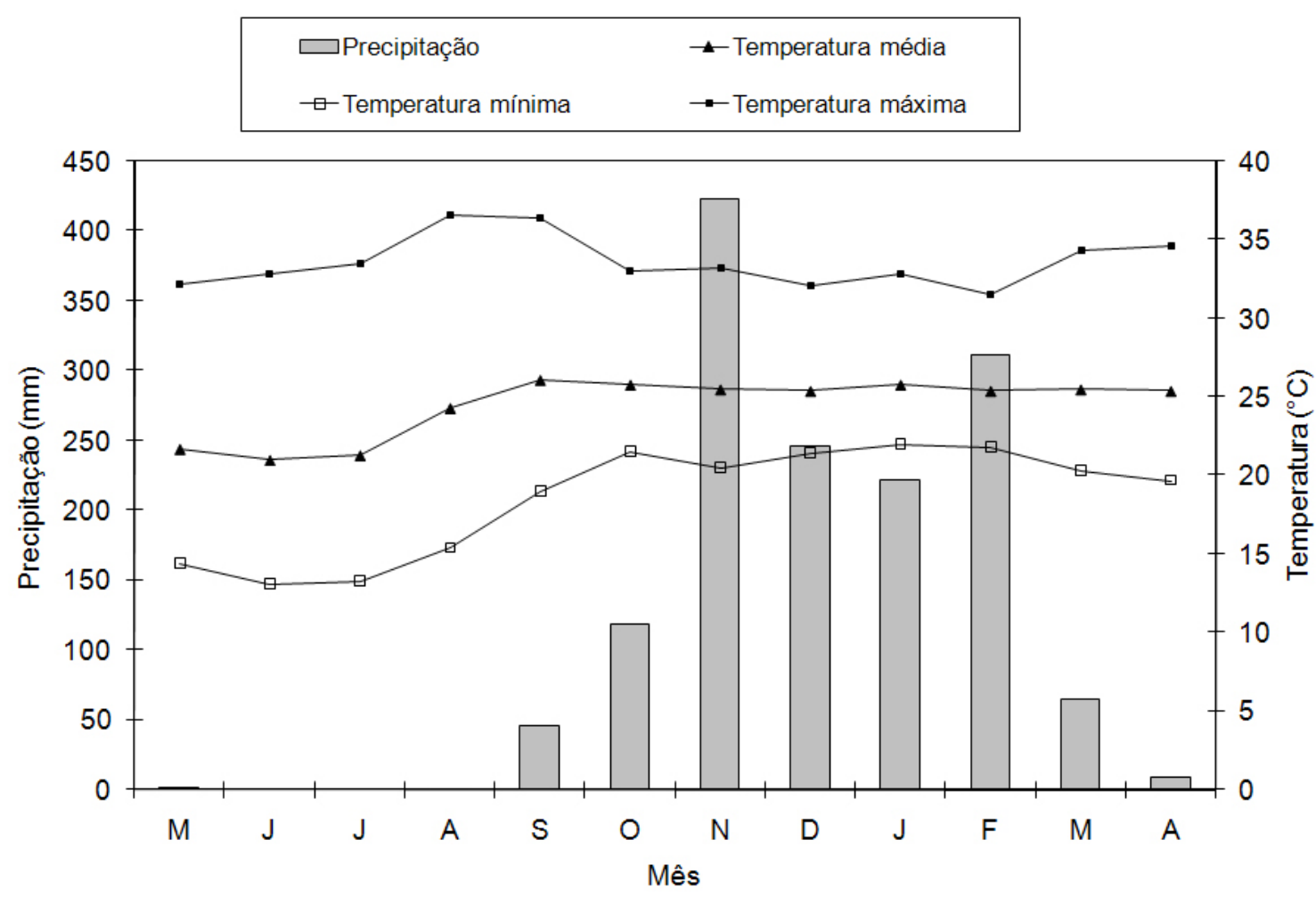

Figura 1 - Climatograma para o Parque do Bacaba, entre maio de 2006 e abril de 2007, em Nova Xavantina, Mato Grosso.

Fonte: Estação Metereológica da UNEMAT, Campus de Nova Xavantina, Mato Grosso.

No Pantanal, B. orbignyana constitui formações dominantes comuns em áreas arenosas, as quais são popularmente conhecidas por canjiqueiral (Marimon \& Lima, 2001; Silva et al., 2000). É uma espécie generalista, podendo ocorrer em diferentes fitofisionomias (Marimon \& Lima, 2001), sendo bastante utilizada na alimentação humana na região do Pantanal (Pott et al., 2004; Silva et al., 2000). No município de Nova Xavantina, B. orbignyana vem sendo explorada em áreas de ocorrência natural e cultivada por pequenos produtores.

B. crassa, conhecida também como muricivermelho ou murici-cascudo, é muito usada em medicina popular (Sannomiya et al., 2005), sendo frequente em áreas de cerradão no Parque do Bacaba (Marimon Junior \& Haridasan, 2005), bem como em áreas de cerrado stricto sensu em Água Boa, Mato Grosso (Felfili et al., 2002).

$B$. verbascifolia é uma espécie arbórea de ampla distribuição no bioma Cerrado (Ratter et al., 2003), porém apresenta densidade variável, de acordo com a fitofisionomia e a região (Felfili et al., 2002; Oliveira-Filho, 1984). Tam- bém apresenta ocorrência natural em áreas do litoral do nordeste do país. Os frutos têm sabor agridoce e são consumidos in natura ou na forma de doces, sorvetes e licores (Almeida et al., 1998). Analisando os aspectos nutricionais dos frutos desidratados, Guimarães \& Silva (2008) concluíram que estes são adequados para consumo, já que nesta forma apresentam-se ricos em fibras, carboidratos, proteínas e lipídios.

\section{FENOLOGia REPRODUtiva}

Para caracterização das fenofases de floração e frutificação em cada espécie estudada, foram selecionados dez indivíduos adultos em bom estado fitossanitário, com pelo menos $5 \mathrm{~m}$ de distância entre si. Considerou-se como adulto todo indivíduo com evidências de estágio reprodutivo anterior (Antunes \& Ribeiro, 1999). Todos os indivíduos de cada espécie foram marcados na mesma fitofisionomia: $B$. verbascifolia foi estudada em uma área de cerrado típico; $B$. orbignyana, em uma área de cerrado denso em regeneração; e $B$. crassa, em uma área de cerradão. 
As observações fenológicas foram realizadas em intervalos quinzenais, no período entre maio de 2006 e abril de 2007. A época de dispersão dos frutos foi estimada a partir da presença de frutos maduros no chão, ao redor da copa e/ou a partir de observações consecutivas do total de frutos maduros na copa. Considerou-se como maduro todo fruto com pericarpo amarelo, polpa suculenta e pouco resistente.

Para análise dos dados fenológicos, utilizou-se o método proposto por Fournier (1974). Em cada observação, calculou-se o Índice de Fournier (IF), que corresponde à somatória das notas atribuídas a cada indivíduo dividida pelo máximo de intensidade que pode ser alcançado por todos os indivíduos (N) na amostra $\left(\mathrm{IF}=\sum\right.$ notas $\left.\times 100 / 4 \times \mathrm{N}\right)$. Os dados coletados na escala de intervalos de Fournier foram convertidos em presença ou ausência para estimar a sincronia dos indivíduos na espécie (Bencke \& Morellato, 2002).

Foi utilizada a análise de correlação de Spearman (rs) (Zar, 1999) entre a porcentagem de Fournier de cada fenofase e as variáveis climáticas (temperatura mínima e máxima e precipitação) (Martin-Gajardo \& Morellato, 2003). Para aplicação deste teste estatístico, utilizou-se o software BioEstat 3.0 (Ayres et al., 2003).

As espécies foram classificadas em grupos fenológicos de acordo com os padrões estabelecidos na literatura por Sarmiento (1984) e Antunes \& Ribeiro (1999). Sarmiento (1984) classificou as espécies em grupos fenológicos de acordo com a ocorrência do pico de floração em relação à estação chuvosa em: precoces (floração no início da estação chuvosa), intermediárias (floração no meio da estação úmida) e tardias (floração na estação seca). Já Antunes \& Ribeiro (1999) estabeleceram como fenofase curta a que dura até cinco meses e fenofase longa a que dura mais de seis meses.

\section{BiOMETRIA DE FRUTOS E SEMENTES}

Durante o período de reprodução, foram amostrados 200 frutos de cada espécie para as análises biométricas. Os frutos foram coletados de indivíduos diferentes daqueles marcados para observação fenológica. Os frutos de
B. crassa foram coletados de 10 indivíduos, os de $B$. orbignyana de 18 indivíduos e os de B. verbascifolia de 12 indivíduos. Foram coletados frutos maduros e sem evidências de predação. As amostras foram colocadas em sacos plásticos e levadas no mesmo dia para o Laboratório de Biologia da UNEMAT, Campus de Nova Xavantina.

Foram avaliadas as seguintes características: peso, comprimento e largura do fruto; peso, comprimento e largura do endocarpo (endocarpo + sementes); peso da polpa (epicarpo + mesocarpo) e número de sementes por fruto. Não foi avaliado o peso da semente em decorrência da dificuldade de escarificação do endocarpo. Para determinação dos pesos, utilizou-se balança de precisão. Para aferição das medidas, utilizou-se paquímetro com precisão de $0,5 \mathrm{~mm}$. Considerou-se comprimento a porção compreendida entre a região basal e a apical e como largura o diâmetro equatorial (Cruz et al., 2001). O peso da polpa foi estimado a partir do peso do fruto menos o peso do endocarpo. $\mathrm{O}$ número de sementes por fruto foi avaliado a partir do corte do endocarpo. Também se analisou a forma do fruto e do endocarpo dividindo-se o diâmetro pelo comprimento, conforme metodologia utilizada por Moraes \& Alves (1997).

Para o peso do fruto e da polpa, foram elaborados histogramas para verificar a distribuição de frequência em intervalos de classes. Para determinação do número de classes, utilizou-se a regra de Sturges (Toledo \& Ovalle, 1992).

Para cada espécie foram analisadas as relações entre: peso do fruto e da polpa; peso e comprimento do fruto; peso e diâmetro do fruto; peso do fruto e peso do endocarpo; peso e comprimento do endocarpo e peso e diâmetro do endocarpo pelo índice de correlação de Spearman (rs) (Zar, 1999) e o respectivo nível de significância $(\mathrm{P})$. Entre espécies foram comparadas as seguintes variáveis: peso da polpa; peso, comprimento e diâmetro do fruto; e peso, comprimento e diâmetro do endocarpo, pelo teste de Kruskal-Wallis seguido do teste de comparações múltiplas de Dunn, no nível de 5\% (Zar, 1999). As análises estatísticas foram realizadas com o uso do software BioEstat 3.0 (Ayres et al., 2003). 


\section{Resultados e discussão}

FENOLOGIA REPRODUTIVA

FLORAÇÃO

Dos 30 indivíduos observados, apenas um de $B$. orbignyana não apresentou atividade reprodutiva durante o período de estudo.

$B$. verbascifolia floresceu no início da estação chuvosa (setembro a novembro); $B$. orbignyana floresceu durante a estação seca e início das chuvas (junho a outubro); e B. crassa floresceu durante toda a estação seca até o início da estação chuvosa (maio a outubro). $O$ pico de floração de $B$. orbignyana ocorreu em setembro ( $\mathrm{IF}=43,0 \%$ ), de B. verbascifolia em outubro (IF $=66,0 \%$ ), início da estação chuvosa, e de B. crassa em julho, em plena estação seca (IF $=87,5 \%$ ). Embora a floração de $B$. crassa ocorra com mais intensidade em julho, todos os indivíduos permanecem com flores por um período de aproximadamente três meses, de junho a agosto (Figura 2C). Para as três espécies, o pico de floração coincidiu com a maior porcentagem de indivíduos floridos (Figuras 2A, 2B e 2C).

No Pantanal de Mato Grosso do Sul, Pott \& Pott (1986) amostraram indivíduos floridos de $B$. verbascifolia durante o mês de agosto e de B. orbignyana de abril a maio. Conforme Lenza \& Klink (2006), no Cerrado do Planalto Central, a floração de B. verbascifolia coincide com o início das chuvas, confirmando as observações feitas durante o presente trabalho.

Deacordocom os padrões estabelecidos por Sarmiento (1984), B. verbascifolia e B. orbignyana apresentaram floração precoce, enquanto B. crassa apresentou floração tardia (Figuras 2 e 3). De acordo com a duração da fenofase (Antunes \& Ribeiro 1999), B. verbascifolia e B. orbignyana apresentaram floração curta e $B$. crassa, floração longa (Figuras 2 e 3 ).

As estratégias de floração propostas por Sarmiento (1984) parecem representar extremos de distribuição de períodos de floração ao longo de todo o ano (Mantovani \& Martins, 1988). Embora isso ocorra, há maior convergência dessa fenofase para o final da estação seca (Oliveira, 2008), tal como verificado entre as espécies estudadas.

\section{FRUTIFICAÇÃO}

As três espécies frutificaram durante o período chuvoso: de outubro a março para B. verbascifolia; de setembro a março para $B$. orbignyana; e de setembro a janeiro para B. crassa (Figuras 2 e 3). A última espécie também apresentou alguns poucos frutos durante o período seco, os quais não se desenvolveram (Figura 2C). Alguns estudos evidenciam relação entre o tipo de fruto e a época de produção, com frutos secos sendo produzidos principalmente durante a estação seca, e espécies com frutos carnosos frutificando principalmente na estação úmida, como é o caso das espécies estudadas (Frankie et al., 1974; Lieberman, 1982; Morellato et al., 1990).

O pico de frutificação ocorreu no início das chuvas (setembro) para B. crassa (IF = $52,5 \%$ ) e no meio da estação chuvosa (dezembro) para B. verbascifolia (IF $=30,0 \%$ ) e B. orbignyana (IF $=55,0 \%$ ) (Figura 2).

A dispersão dos frutos de cada espécie durou aproximadamente três meses dentro da estação chuvosa, com sobreposição deste evento para B. verbascifolia e B. orbignyana (Figura 2). No Cerrado, Oliveira (2008) observou que as espécies zoocóricas têm pico de frutificação na chuva, com frutos sendo dispersos durante esta estação.

B. verbascifolia e B. crassa apresentaram picos de floração superiores ao de frutificação (Figuras 2A e 2C). Para Penhalber \& Mantovani (1997), nem todas as flores são polinizadas e conseguem desenvolver frutos, de forma que muitas perdas ocorrem durante este processo. Já para $B$. orbignyana não houve diferença tão marcante entre os picos de floração e frutificação (Figura 2B), sugerindo eficiência na polinização e maior produção de frutos, características favoráveis à viabilidade comercial da espécie.

Quanto aos padrões de frutificação encontrados, todas as espécies apresentaram períodos longos para a fenofase, de acordo a classificação proposta por Antunes \& Ribeiro (1999).

A sincronia dos indivíduos (índice de atividade) das três espécies foi maior do que o índice de intensidade de Fournier (Figura 2). Esse fato parece ser comum na análise individual de espécies, como observado também por Bencke \& Morellato (2002) em uma compilação de dados fenológicos para três forma- 


\begin{tabular}{|ll|}
\hline$\leftarrow$ Fournier floração & $\rightarrow$-Fournier frutificação \\
$-\square$ Indivíduos em floração & $\square$-Indivíduos em frutificação \\
\hline
\end{tabular}
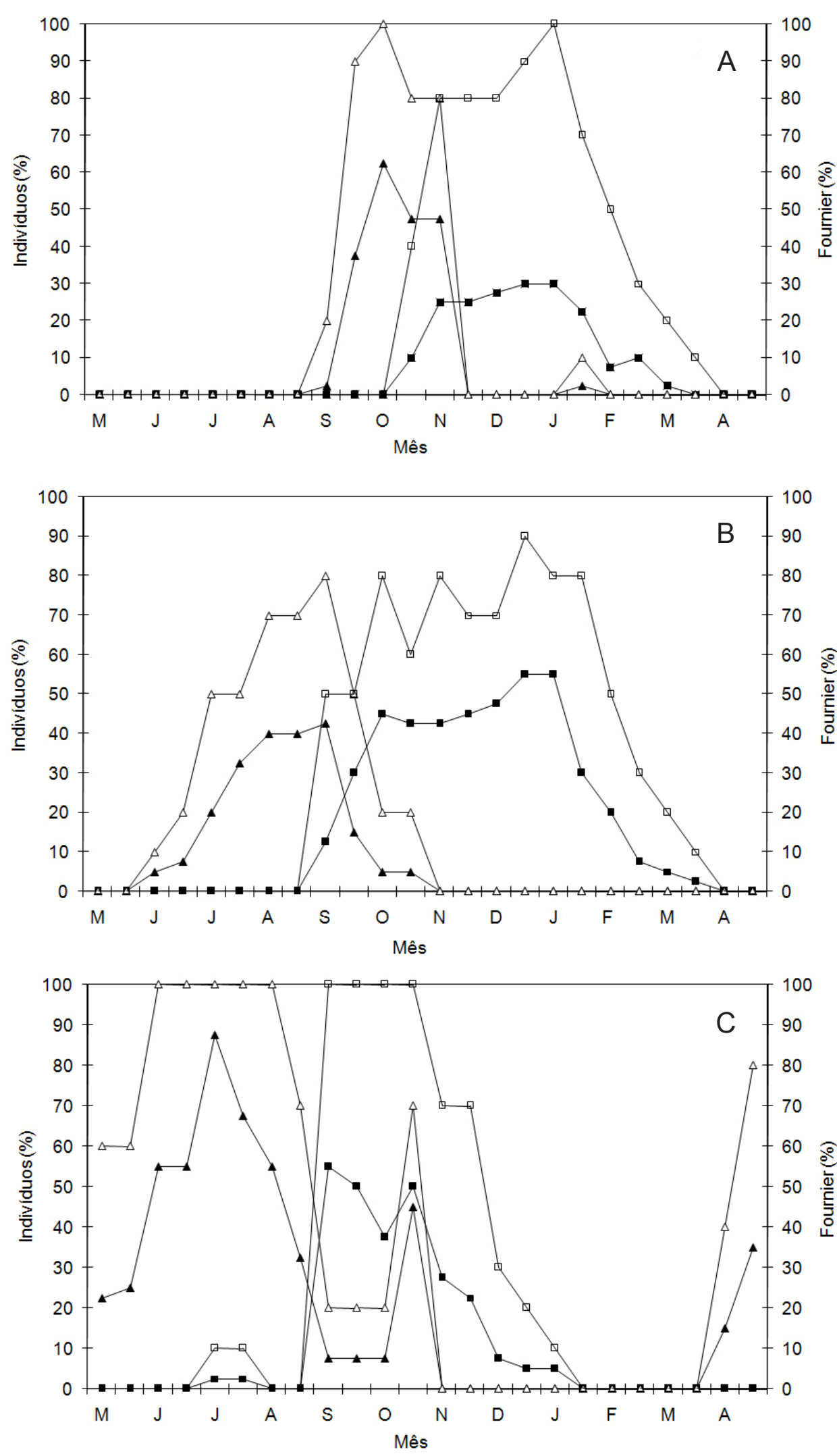

Figura 2 - Fenologia reprodutiva de: A. Byrsonima verbascifolia, B. Byrsonima orbignyana e C. Byrsonima crassa no período entre maio de 2006 e abril de 2007 no Parque do Bacaba, em Nova Xavantina, Mato Grosso. 


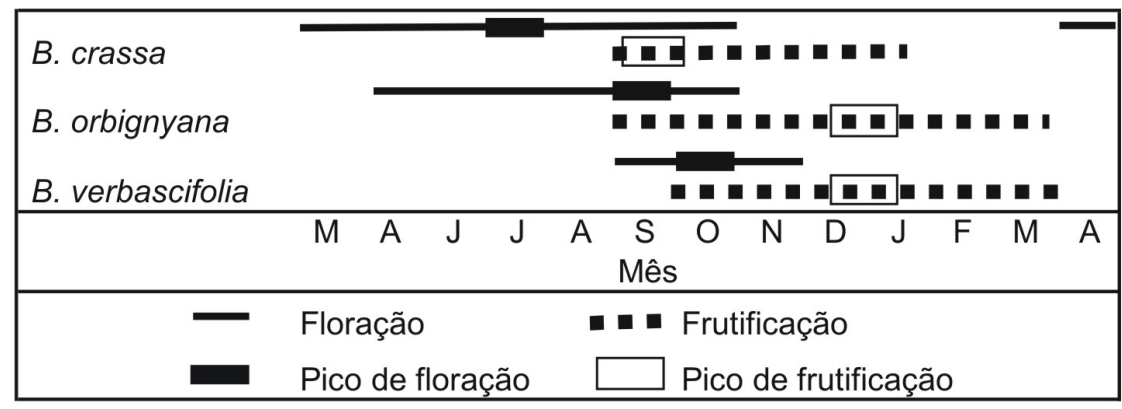

Figura 3 - Fenograma das fenofases reprodutivas de Byrsonima crassa, Byrsonima orbignyana e Byrsonima verbascifolia no período entre maio de 2006 e abril de 2007 no Parque do Bacaba, em Nova Xavantina, Mato Grosso.

ções florestais na Mata Atlântica, assim como por Santos \& Takaki (2005) em uma floresta estacional semidecidual de São Paulo. Entretanto, em estudos de comunidades, como o realizado por Martin-Gajardo \& Morellato (2003), o índice de atividade pode ser igual à porcentagem de Fournier. Além disso, o índice de atividade dos indivíduos pode também coincidir com a época de maior intensidade de Fournier, como verificado no presente estudo.

Os dois índices - de atividade e de intensidade de Fournier - fornecem informações distintas e complementares. Bencke \& Morellato (2002) sugerem que estes sejam usados de forma combinada em estudos fenológicos de populações para a análise e a representação dos dados. As autoras afirmaram que o pico de intensidade da fenofase pode estar relacionado a fatores bióticos, tais como presença, atividade ou abundância de polinizadores ou dispersores, uma vez que tem relação direta com a abundância do recurso. Já o pico de atividade pode estar mais relacionado com características endógenas e com fatores abióticos que atuam sobre o funcionamento da planta, determinando ou restringindo a ocorrência do evento.

\section{CoRRELAÇÃO ENTRE AS FENOFASES E VARIÁVEIS CLIMÁTICAS}

Quanto à floração, B. verbascifolia apresentou correlação positiva significativa com a precipitação e a temperatura mínima e B. crassa, correlação inversa com a precipitação e a temperatura mínima, não tendo sido significativa a relação com a temperatura máxima para as duas espécies. B. orbignyana apresentou correlação positiva com a temperatura máxima, não sendo significativa a relação com as outras variáveis (Tabela 1 ).

Gouveia \& Felfili (1998) encontraram correlação inversa e significativa entre floração e precipitação em uma comunidade de Cerrado no Distrito Federal, tal qual observado para $B$. crassa neste estudo. De acordo com as autoras, esta pode ser uma estratégia de atração de polinizadores, uma vez que na estação seca, as flores seriam um dos poucos recursos disponíveis para a alimentação da fauna. Por outro lado, Mantovani \& Martins (1988) e Batalha \& Mantovani (2000), estudando áreas diferentes de Cerrado em São Paulo, verificaram número maior de espécies do componente arbustivo-

Tabela 1 - Índice de correlação de Spearman (rs) entre as fenofases de floração e frutificação de Byrsonima crassa, Byrsonima orbignyana e Byrsonima verbascifolia e a precipitação (1), temperaturas mínimas (2) e máximas (3) no período entre maio de 2006 e abril de 2007 no Parque do Bacaba, em Nova Xavantina, Mato Grosso.

\begin{tabular}{|c|c|c|c|c|c|c|}
\hline \multirow{2}{*}{ Espécie } & \multicolumn{3}{|c|}{ Flor } & \multicolumn{3}{|c|}{ Fruto } \\
\hline & 1 & 2 & 3 & 1 & 2 & 3 \\
\hline B crassa & $-0,799 *$ & $-0,678^{*}$ & 0,357 & 0,400 & 0,313 & 0,163 \\
\hline B. orbignyana & $-0,463$ & $-0,399$ & $0,587^{*}$ & $0,834^{*}$ & $0,776^{*}$ & $-0,259$ \\
\hline B verbascifolia & $0,537^{*}$ & $0,514^{*}$ & 0,269 & $0,885^{*}$ & $0,862^{*}$ & $-0,428$ \\
\hline
\end{tabular}

* Significativo no nível de 5\% de probabilidade. 
arbóreo florescendo no início das chuvas, época de maior calor e umidade.

Nas espécies que apresentam diferentes grupos de polinizadores, algumas variáveis climáticas parecem funcionar como gatilhos ambientais que desencadeiam a floração (Oliveira, 2008). Por outro lado, naquelas que compartilham os mesmos polinizadores, como é o caso da família Malpighiaceae, polinizada por visitantes especializados na coleta de óleos florais, principalmente abelhas da tribo Centridini (Anderson, 1979), a competição por polinizadores parece ser o fator mais importante no ajustamento dos períodos de floração (Oliveira, 2008). Esse ajustamento, que diminui a competição por polinizadores, parece ser bastante frequente nas comunidades vegetais (Barros, 1998, 2002; Costa et al., 2006; Machado \& Semir, 2006).

As espécies de Byrsonima estudadas apresentam esse comportamento, pois os picos de floração não se sobrepõem (Figura 3). Costa et al. (2006) também observaram esse padrão para uma comunidade de Malpighiaceae em áreas de dunas na Bahia. Machado \& Semir (2006), estudando uma comunidade de bromélias polinizadas por beija-flores na Mata Atlântica, encontraram floração sequencial e contínua. Segundo os autores, além de evitar a competição, a floração sequencial disponibiliza alimento aos polinizadores ao longo do ano, o que propicia maximização do sucesso reprodutivo das espécies.

Entretanto, para o Cerrado, parece haver variação nesse padrão. Barros $(1998,2002)$ verificou a ocorrência de número maior de espécies do mesmo gênero, que dividem os mesmos polinizadores, sincronizando a floração durante o período seco, com poucas espécies florescendo durante o período chuvoso.

A frutificação das três espécies apresentou correlação positiva com a precipitação e a temperatura mínima; entretanto, essa correlação não foi significativa para $B$. crassa (Tabela 1). Contudo, observou-se que o período de frutificação desta espécie ocorre predominantemente na estação chuvosa (Figura 3).

Nos Cerrados do Brasil Central, que tem estações seca e chuvosa bem marcadas, a pluviosidade tem sido apontada como condicionante da fenodinâmica (Felfili et al., 1999).
Alguns trabalhos indicam que, no Cerrado, a frutificação das espécies anemocóricas concentra-se na estação seca, enquanto as espécies zoocóricas frutificam principalmente na estação chuvosa (Batalha \& Mantovani, 2000; Fernandes-Bulhão \& Figueiredo, 2002; Mantovani \& Martins, 1988; Oliveira, 2008; Ribeiro et al., 1982). De acordo com Martin-Gajardo \& Morellato (2003), ambientes com baixa sazonalidade climática oferecem condições pouco restritivas para o desenvolvimento dos frutos durante todo o ano. Como a região estudada apresenta estações bem definidas, o estresse hídrico pode limitar o desenvolvimento de frutos durante a estação desfavorável. $\mathrm{O}$ fato de os frutos de $B$. crassa surgidos na estação seca não terem se desenvolvido corrobora essa ideia (Figura 2).

A precipitação parece ser a variável climática que melhor explica a frutificação das espécies analisadas (Tabela 1). Ribeiro \& Walter (1998) observaram que as outras variáveis climáticas (temperatura e umidade relativa do ar) também mudam em função da precipitação.

\section{Biometria dos FRUTOS E SEMENTES}

Os principais dados biométricos dos frutos e endocarpos das três espécies estudadas são apresentados nas Tabelas 2 e 3. Observouse variação no comprimento e diâmetro dos frutos e endocarpos das três espécies.

O comprimento dos frutos apresentou valores significativamente diferentes entre todas as espécies $(\mathrm{H}=427,65, \mathrm{p}<0,05)$, ocorrendo o mesmo com o diâmetro dos frutos $(\mathrm{H}=508,21, \mathrm{p}<0,05)$. B. crassa apresentou frutos com menores dimensões e $B$. verbascifolia, os maiores frutos (Tabela 2). Gusmão et al. (2006) registraram médias de 10,05 $\mathrm{mm}$ de comprimento e 11,93 mm de diâmetro para frutos maduros de B. verbascifolia coletados em Minas Gerais, valores menores do que as médias encontradas no presente estudo (Tabela 2).

Os comprimentos dos endocarpos de B. orbignyana e B. verbascifolia não apresentaram diferenças significativas entre si pelo teste de Dunn (Tabela 2), indicando semelhança nos endocarpos dessas duas espécies. Quanto ao diâmetro, todas as espécies diferiram estatisticamente entre si $(\mathrm{H}=428,98, \mathrm{p}<0,05)$. 
Tabela 2 - Comprimento e diâmetro dos frutos e endocarpos de Byrsonima crassa, Byrsonima orbignyana e Byrsonima verbascifolia coletados no Parque do Bacaba, em Nova Xavantina, Mato Grosso, em 2007.

\begin{tabular}{|c|c|c|c|c|c|}
\hline Espécie & Máximo & Médio & Mínimo & $\mathrm{DP}^{1}$ & $\mathrm{CV}(\%)^{2}$ \\
\hline \multicolumn{6}{|c|}{ Comprimento do fruto $(\mathrm{mm})$} \\
\hline B. crassa & 1,10 & 0,86 a & 0,59 & $\pm 0,10$ & 12,12 \\
\hline B. orbignyana & 19,70 & $14,89 \mathrm{~b}$ & 11,40 & $\pm 1,06$ & 7,13 \\
\hline B. verbascifolia & 21,50 & $16,26 \mathrm{c}$ & 12,20 & $\pm 1,78$ & 10,94 \\
\hline \multicolumn{6}{|c|}{ Diâmetro do fruto $(\mathrm{mm})$} \\
\hline B. crassa & 0,92 & 0,79 a & 0,60 & $\pm 0,07$ & 9,05 \\
\hline B. orbignyana & 19,50 & $15,81 \mathrm{~b}$ & 12,40 & $\pm 1,37$ & 8,66 \\
\hline B.verbascifolia & 28,50 & $19,53 \mathrm{c}$ & 15,00 & $\pm 1,86$ & 9,51 \\
\hline \multicolumn{6}{|c|}{ Comprimento do endocarpo (mm) } \\
\hline B. crassa & 0,80 & 0,63 a & 0,40 & $\pm 0,06$ & 9,09 \\
\hline B. orbignyana & 10,80 & $8,74 \mathrm{~b}$ & 6,20 & $\pm 0,80$ & 9,19 \\
\hline B.verbascifolia & 11,50 & $8,81 \mathrm{~b}$ & 6,50 & $\pm 0,93$ & 10,54 \\
\hline \multicolumn{6}{|c|}{ Diâmetro do endocarpo (mm) } \\
\hline B. crassa & 0,66 & $0,54 \mathrm{a}$ & 0,40 & $\pm 0,07$ & 12,57 \\
\hline B. orbignyana & 9,90 & $7,80 \mathrm{~b}$ & 6,00 & $\pm 0,88$ & 11,34 \\
\hline B. verbascifolia & 11,90 & $8,60 \mathrm{c}$ & 6,50 & $\pm 0,96$ & 11,19 \\
\hline
\end{tabular}

${ }^{1} \mathrm{DP}=$ desvio padrão.

${ }^{2} \mathrm{CV}=$ coeficiente de variação.

Médias seguidas pela mesma letra não diferem entre si pelo teste de Dunn $(\mathrm{p}<0,05)$.

Tabela 3 - Peso de frutos, endocarpo e polpa de Byrsonima crassa, Byrsonima orbignyana e Byrsonima verbascifolia no Parque do Bacaba, em Nova Xavantina, Mato Grosso, em 2007.

\begin{tabular}{|c|c|c|c|c|c|}
\hline Espécie & Máximo & Médio & Mínimo & DP1 & $\mathrm{CV}(\%)^{2}$ \\
\hline \multicolumn{6}{|c|}{ Peso de fruto (g) } \\
\hline B. crassa & 0,43 & $0,30 \mathrm{a}$ & 0,17 & $\pm 0,05$ & 17,80 \\
\hline B. orbignyana & 3,97 & $2,41 \mathrm{~b}$ & 1,41 & $\pm 0,51$ & 21,24 \\
\hline B. verbascifolia & 7,03 & $3,81 \mathrm{c}$ & 2,01 & $\pm 0,99$ & 25,99 \\
\hline \multicolumn{6}{|c|}{ Peso de endocarpo (g) } \\
\hline B. crassa & 0,15 & $0,10 \mathrm{a}$ & 0,05 & $\pm 0,02$ & 20,16 \\
\hline B. orbignyana & 0,68 & $0,38 \mathrm{~b}$ & 0,21 & $\pm 0,10$ & 25,83 \\
\hline B. verbascifolia & 1,03 & $0,44 \mathrm{c}$ & 0,25 & $\pm 0,12$ & 27,31 \\
\hline \multicolumn{6}{|c|}{ Peso de polpa (g) } \\
\hline B. crassa & 0,33 & $0,20 \mathrm{a}$ & 0,10 & $\pm 0,04$ & 21,56 \\
\hline B. orbignyana & 3,33 & $2,04 \mathrm{~b}$ & 1,17 & $\pm 0,44$ & 21,58 \\
\hline B. verbascifolia & 6,48 & $3,37 c$ & 1,70 & $\pm 0,93$ & 27,59 \\
\hline
\end{tabular}

${ }^{1} \mathrm{DP}=$ desvio padrão.

${ }^{2} \mathrm{CV}=$ coeficiente de variação.

Médias seguidas pela mesma letra não diferem entre si pelo teste de Dunn $(p<0,05)$. 
B. verbascifolia e B. orbignyana apresentaram médias de comprimento do fruto menores do que o diâmetro, mostrando tendência a frutos mais achatados, enquanto para B. crassa aconteceu o contrário, indicando tendência para frutos compridos (Tabela 2). Os endocarpos das três espécies apresentaram médias de comprimento maiores do que o diâmetro, indicando tendência a endocarpos alongados.

Houve diferenças significativas para os pesos dos frutos $(\mathrm{H}=489,27, \mathrm{p}<0,05)$, dos endocarpos $(\mathrm{H}=415,32, \mathrm{p}<0,05)$ e da polpa $(\mathrm{H}=493,92 \mathrm{p}<0,05)$ entre as três espécies (Tabela 3). B. crassa apresentou frutos com menor peso, enquanto $B$. verbascifolia apresentou os mais pesados. No presente estudo, os frutos de B. verbascifolia apresentaram peso entre 2,01 g e 7,02 g. Em Montes Claros, Minas Gerais, Gusmão et al. (2006) registraram frutos maduros desta mesma espécie com pesos entre $0,27 \mathrm{~g}$ e 2,34 g. No Distrito Federal, foram encontrados frutos com pesos entre 1,0 $\mathrm{g}$ e 4,0 g (Silva et al., 1994). Essas diferenças demonstram grande variabilidade genética e podem estar associadas à plasticidade fenotípica, determinada por variações ambientais das diferentes localidades geográficas (Gusmão et al., 2006).

Na Figura 4 são apresentados os gráficos da distribuição de frequência do peso dos frutos das três espécies. Não há grande variação na frequência de frutos de $B$. crassa nos diferentes intervalos de classe, pois apenas os frutos muito pequenos e os maiores são menos frequentes. Para as outras duas espécies, os frutos maiores são pouco frequentes, estando a maioria dos frutos de B. orbignyana entre $1,70 \mathrm{~g}$ e $2,83 \mathrm{~g}$, o que representa $76 \%$ do total, enquanto $76,5 \%$ dos frutos de $B$. verbascifolia estão entre $2,58 \mathrm{~g}$ e 4,80 g. Baixa frequência de frutos maiores, como observado para $B$. orbignyana e $B$. verbascifolia, pode refletir o impacto do extrativismo sobre a variabilidade genética das plantas, tendo em vista que as coletas priorizam os frutos maiores e de melhor qualidade. Em se tratando de espécies arbóreas tropicais, geralmente diásporos grandes aumentam o sucesso germinativo, o crescimento e a sobrevivência da plântula, resultando em indivíduos mais vigorosos e competitivamente superiores (Moraes \& Alves, 2002).
A polpa contribui com $68,07 \%$ do peso total do fruto de B. crassa, $84,41 \%$ do peso dos frutos de B. orbignyana e $88,43 \%$ do peso dos frutos de B. verbascifolia. Gusmão et al. (2006) encontraram valores diferentes para B. verbascifolia $(73,63 \%)$, o que pode ser influenciado por diferenças climáticas e/ou fenotípicas nas populações de diferentes localidades.

Os frutos carnosos são considerados como uma estratégia da espécie para atrair os animais dispersores (Mantovani \& Martins, 1988). Além de refletir a disponibilidade de alimento para a fauna silvestre, a quantidade de polpa dos frutos também influencia na valoração econômica para o extrativismo. Em seu estudo, Lima et al. (2002) concluíram que o umbu-cajá (Spondias spp) mostrou condições adequadas para comercialização por apresentar rendimento em polpa acima de $50 \%$. Considerando esse critério, as três espécies estudadas apresentam condições de comercialização. Entretanto, B. crassa é a menos indicada para comercialização com fins alimentícios, já que são necessários muitos frutos para se obter $1 \mathrm{~kg}$ de polpa (Tabela 4), além de serem mais adstringentes e, portanto, menos palatáveis. A avaliação do potencial de comercialização também depende de outros aspectos, como a produtividade por indivíduo e a densidade de indivíduos na área, o que não foi avaliado neste trabalho.

De forma geral, as três espécies apresentaram muitos frutos com rendimento médio de polpa e baixa frequência de frutos com grande quantidade de polpa. Os frutos de B. crassa que apresentaram peso de polpa entre 0,16 $\mathrm{g}$ e 0,23 g representaram $62 \%$ do total; os frutos de B. orbignyana que apresentaram peso de polpa entre 1,42 g e 2,37 g representaram $74 \%$ do total; os frutos de B. verbascifolia que apresentaram peso de polpa entre 2,24 g e 4,36 g representaram $76 \%$ do total (Figura 5).

O tamanho do fruto é diretamente proporcional à quantidade de polpa. Houve correlação positiva e significativa entre o peso do fruto e o peso da polpa para as três espécies (Tabela 5). Assim, frutos maiores têm maior peso em decorrência da maior quantidade de polpa. Gusmão et al. (2006) chegaram às mesmas conclusões estudando uma população de B. verbascifolia em Minas Gerais. 

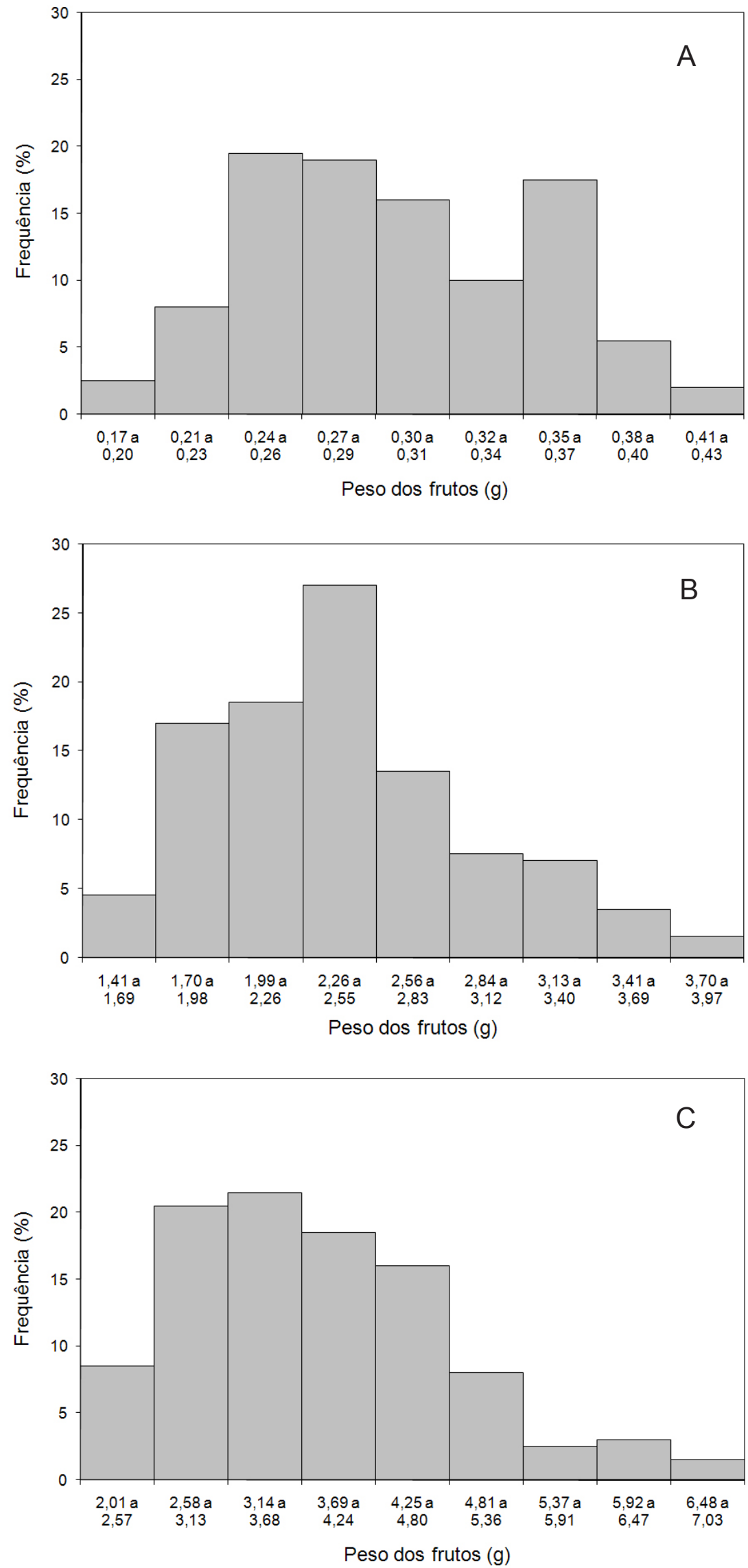

Figura 4 - Distribuição de frequência do peso dos frutos de A. Byrsonima crassa, B. Byrsonima orbignyana e C. Byrsonima verbascifolia coletados em 2007 no Parque do Bacaba, em Nova Xavantina, Mato Grosso. 
Tabela 4 - Estimativas para se obter $1 \mathrm{~kg}$ de frutos, polpa e endocarpo de Byrsonima crassa, Byrsonima orbignyana e Byrsonima verbascifolia coletados em 2007, no Parque do Bacaba, em Nova Xavantina, Mato Grosso.

\begin{tabular}{lccc}
\hline Espécie & Frutos em $\mathbf{1} \mathbf{~ k g}$ (n) & Frutos para $\mathbf{1}$ kg de polpa (n) & Endocarpos em $\mathbf{1} \mathbf{~ k g}$ (n) \\
\hline B. crassa & 3.360 & 4.936 & 10.524 \\
B. orbignyana & 414 & 491 & 2.660 \\
B. verbascifolia & 262 & 297 & 2.267 \\
\hline
\end{tabular}

Para todas as espécies, também houve correlação positiva e significativa entre o peso do fruto e do endocarpo, demonstrando que o endocarpo tende a ser maior conforme o fruto aumenta de tamanho. Entretanto, esses valores de correlação são menores do que os apresentados para o peso do fruto e da polpa (Tabela 5). Portanto, frutos maiores apresentam maior peso, o que occore mais em função da polpa do que do endocarpo propriamente dito.

Também houve correlação positiva e significativa entre o peso e o comprimento dos frutos e entre o peso e o diâmetro destes para todas as espécies (Tabela 5), demonstrando que existe expansão de todas as dimensões do fruto conforme este aumenta de tamanho. Analisando parâmetros biométricos de frutos de butiazeiro (Butia capitata (Mart.) Becc. Arecaceae), Pedron et al. (2004) também observaram a existência de correlação linear positiva entre o peso e o tamanho dos frutos.

Quanto aos endocarpos, houve correlação positiva e significativa entre o peso e o comprimento, bem como entre o peso e a largura destes (Tabela 5). Esses resultados indicam que existe aumento simultâneo das dimensões enquanto o endocarpo aumenta de tamanho. Entretanto, os valores de correlação entre o peso e o diâmetro do endocarpo são maiores do que os encontrados para o peso e o comprimento deste, o que pode indicar a mesma tendência discutida anteriormente para os frutos, ou seja, endocarpos maiores também tendem a ser mais achatados.

De acordo com Farias Neto et al. (2004), as estimativas de correlação são úteis para o melhoramento de plantas. Por exemplo, quando determinado caráter de interesse é de difícil avaliação, o processo seletivo torna-se mais simples se este caráter apresentar alta correla- ção positiva com outro de fácil avaliação, haja vista que aumentos em um caráter tendem a ser acompanhados de aumentos no outro. Da mesma forma, a seleção para inibição de um caráter indesejado que esteja altamente relacionado com outro de interesse pode ser inviável.

Quanto ao número de sementes desenvolvidas nos endocarpos, todas as espécies apresentaram de uma a três sementes formadas (Figura 6). A maioria (47\%) dos frutos de B. orbignyana apresentou uma semente, enquanto a maioria dos frutos de B. crassa (57\%) e de B. verbascifolia (32\%) apresentou duas sementes cada. B. crassa apresentou maior número de frutos com duas e três sementes (Figura 6).

Quanto à forma dos frutos, B. crassa apresentou a maioria dos frutos compridos (69\%) e B. orbignyana e B. verbascifolia apresentaram mais frutos achatados $(71 \%$ e $99 \%$, respectivamente), tendo havido baixa frequência de frutos esféricos. B. verbascifolia não apresentou frutos esféricos (Figura 7 A). As três espécies apresentaram a maior parte dos endocarpos compridos, havendo baixa frequência de endocarpos esféricos e achatados (Figura 7 B).

As dimensões do fruto, especialmente o diâmetro, têm mostrado associação significativa com o tipo de dispersor, tendendo a aumentar com o incremento da participação de mamíferos entre os agentes dispersores (Jordano, 1995). Isto parece ser verdadeiro para as espécies estudadas, ou seja, $B$. crassa, que é dispersada por aves (Oliveira \& Paula, 2001), apresenta frutos menores e diâmetro menor do que o comprimento (Tabelas 2 e 3), enquanto $B$. verbascifolia, que tem um canídeo entre os agentes dispersores (Dalponte \& Lima, 1999), apresenta frutos maiores e com diâmetro maior do que o comprimento (Tabelas 2 e 3). 

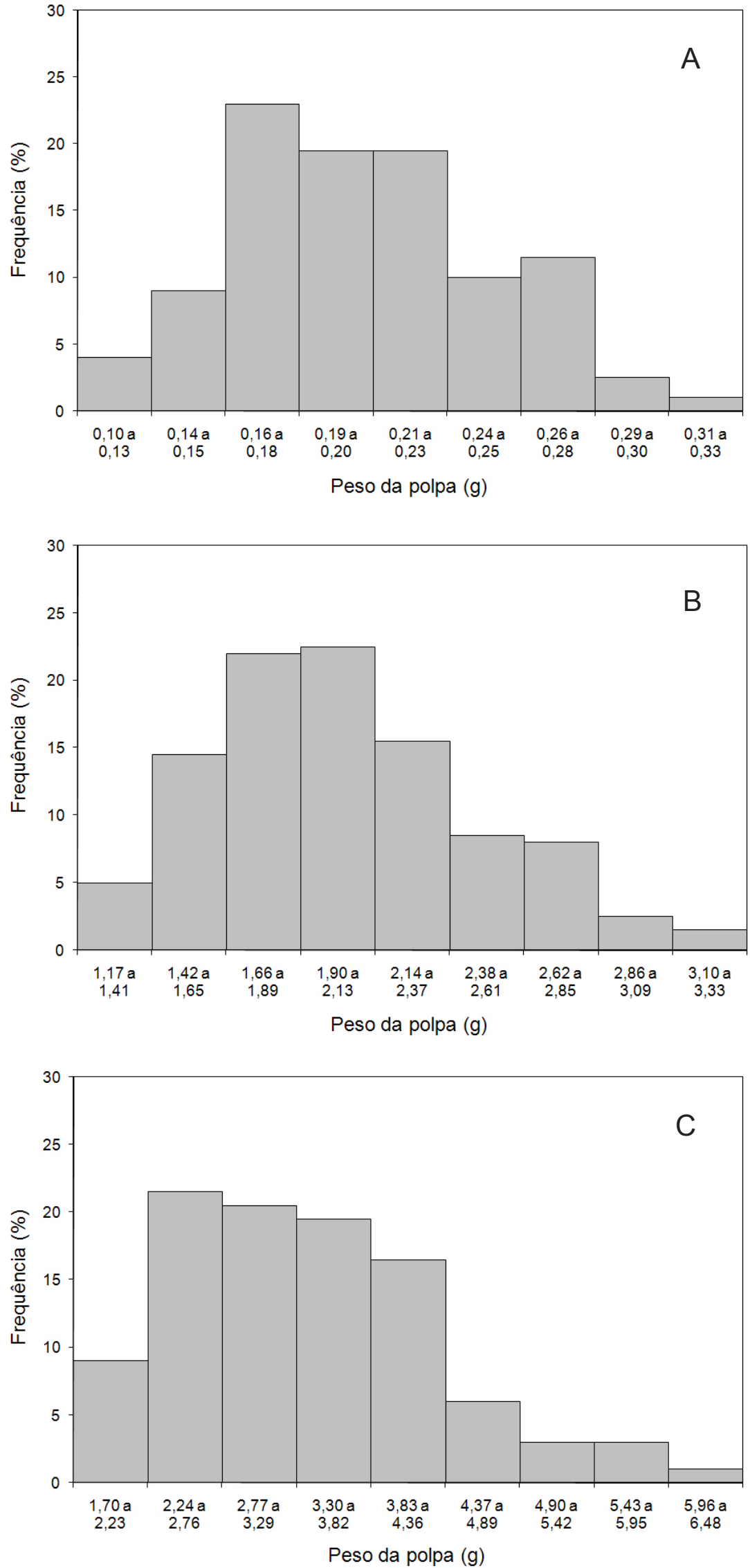

Figura 5 - Distribuição de frequência do peso da polpa dos frutos de A. Byrsonima crassa, B. Byrsonima orbignyana e C. Byrsonima verbascifolia coletados em 2007 no Parque do Bacaba, em Nova Xavantina, Mato Grosso. 
Tabela 5 - Índice de correlação de Spearman (rs) para as variáveis biométricas de Byrsonima crassa, Byrsonima orbignyana e Byrsonima verbascifolia do Parque do Bacaba, em Nova Xavantina, Mato Grosso, em 2007.

\begin{tabular}{lcccccc}
\hline Espécie & PF X PP & PFX PE & PF X CF & PF X DF & PE X CE & PE X DE \\
\hline B. crassa & $0,933^{*}$ & $0,633^{*}$ & $0,589^{*}$ & $0,720^{*}$ & $0,204^{*}$ & $0,568^{*}$ \\
B. orbignyana & $0,990^{*}$ & $0,760^{*}$ & $0,487^{*}$ & $0,908^{*}$ & $0,399^{*}$ & $0,874^{*}$ \\
B. verbascifolia & $0,993^{*}$ & $0,574^{*}$ & $0,735^{*}$ & $0,861^{*}$ & $0,580^{*}$ & $0,771^{*}$ \\
\hline
\end{tabular}

$\mathrm{PF}=$ peso do fruto $(\mathrm{g}) ; \mathrm{PP}=$ peso da polpa $(\mathrm{g}) ; \mathrm{PE}=$ peso do endocarpo $(\mathrm{g}) ; \mathrm{CF}=$ comprimento do fruto $(\mathrm{mm})$; $\mathrm{DF}=$ diâmetro do fruto $(\mathrm{mm}) ; \mathrm{CE}=$ comprimento do endocarpo $(\mathrm{mm}) ; \mathrm{DE}=$ diâmetro do endocarpo $(\mathrm{mm})$. Peso em gramas; comprimento e diâmetro em milímetros.

* Significativo no nível de 5\% de probabilidade.

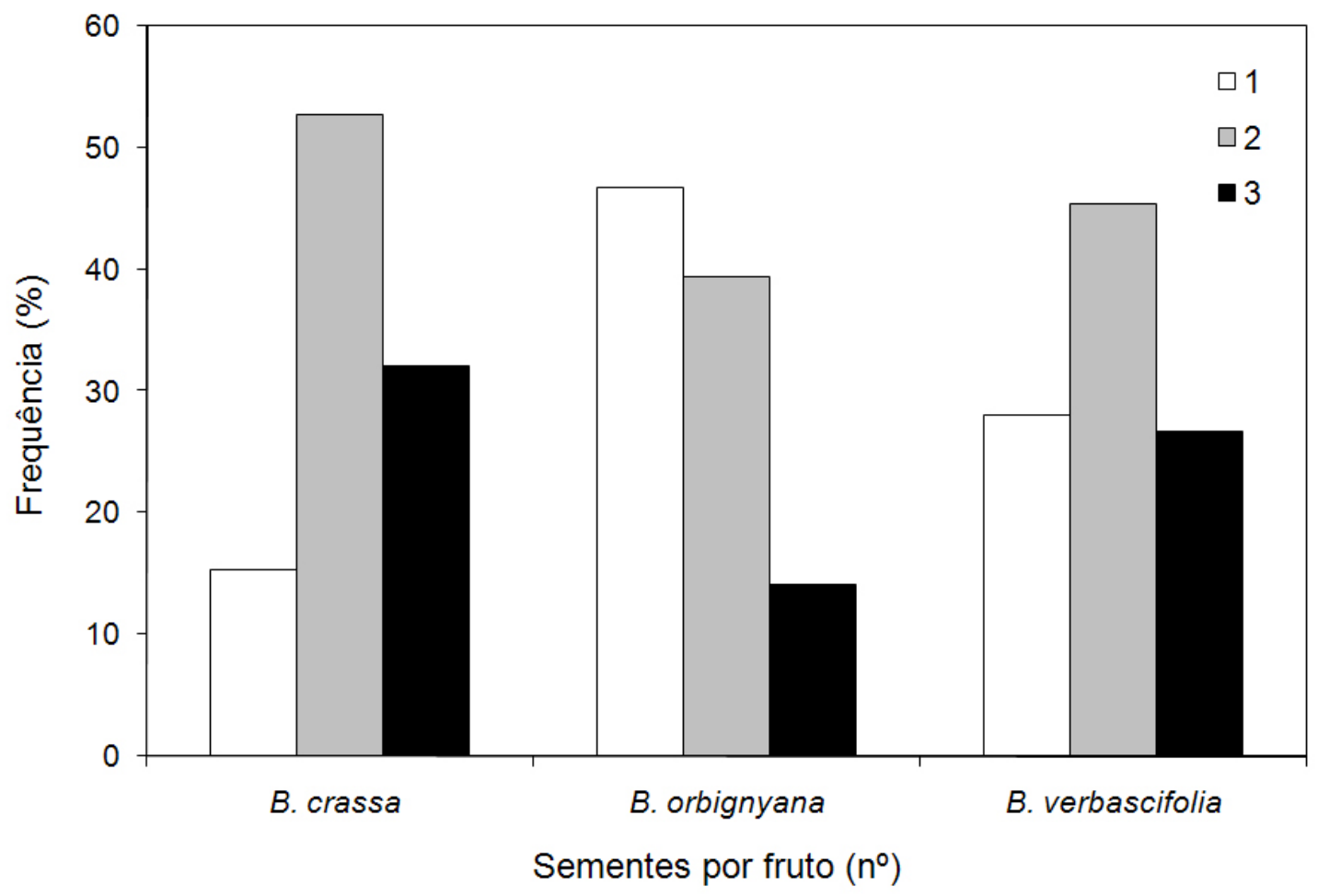

Figura 6 - Número de sementes por fruto de Byrsonima crassa, Byrsonima orbignyana e Byrsonima verbascifolia coletados em 2007 no Parque do Bacaba, em Nova Xavantina, Mato Grosso.

As espécies de Byrsonima estudadas no Parque do Bacaba floresceram durante a estação seca e no início das chuvas. A frutificação está associada aos períodos de maior precipitação na região, de setembro a março. Entretanto, a sobreposição dos períodos de maturação e dispersão das espécies restringe a disponibilidade de frutos a um período de três meses. $B$. verbascifolia e $B$. orbignyana apresentaram os maiores frutos e o maior rendimento de polpa, mostrando-se mais adequadas para a comercialização.

A exploração extrativista destas espécies nativas deve levar em conta as características biológicas dos frutos e o comportamento fenológico das espécies, devendo haver também um manejo racional e sustentável das áreas exploradas, de forma que a coleta dos frutos não gere erosão genética das espécies. 

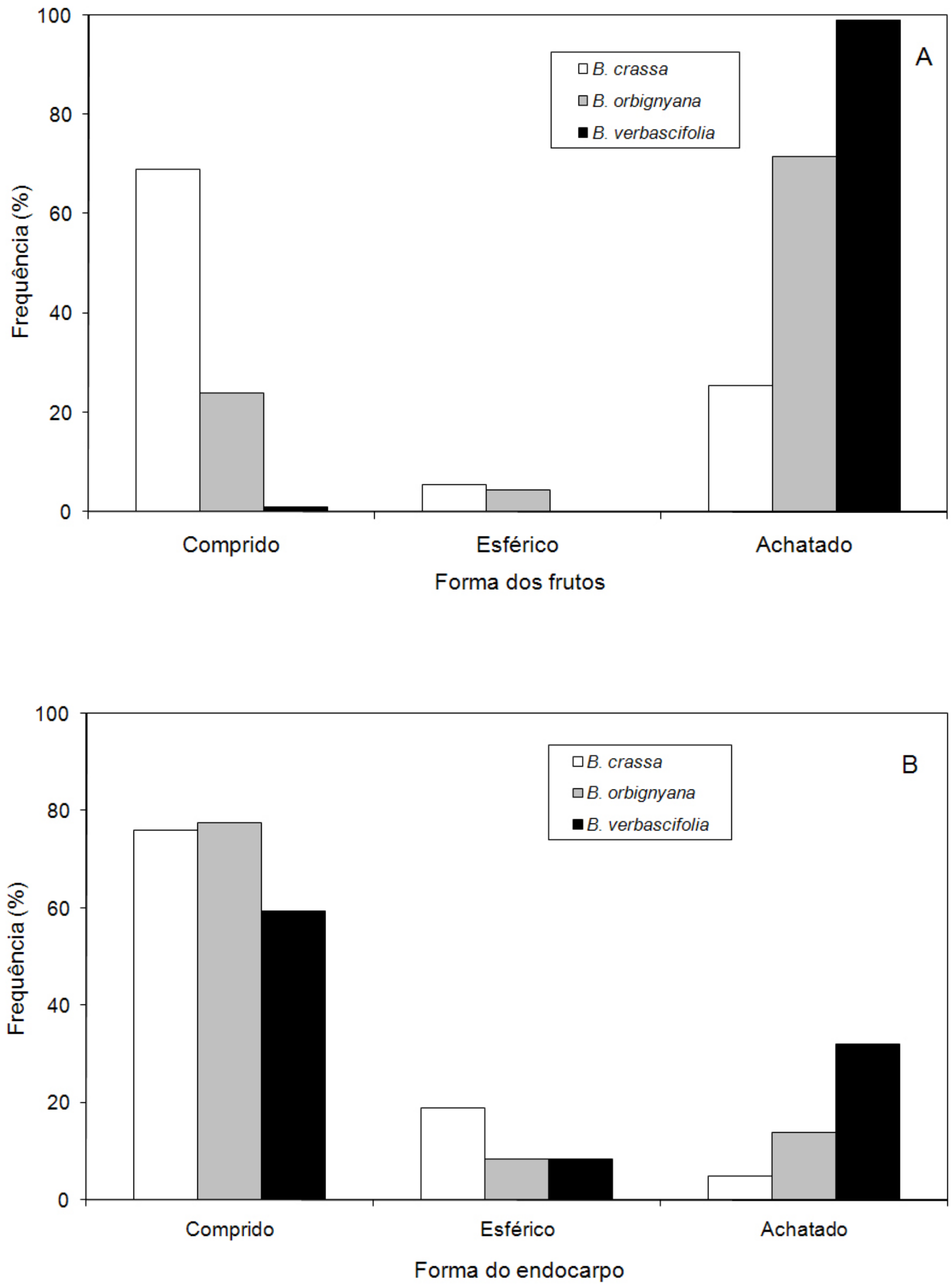

Figura 7 - Frequência de A. forma dos frutos e B. forma dos endocarpos de Byrsonima crassa, Byrsonima orbignyana e Byrsonima verbascifolia coletados em 2007 no Parque do Bacaba, em Nova Xavantina, Mato Grosso. 


\section{ReferênCIAS}

Almeida, S. P., C. E. B. Proença, S. M Sano \& J. F. Ribeiro. 1998. Cerrados: espécies vegetais úteis. EMBRAPA-CPAC, Planaltina, $464 \mathrm{p}$.

Almeida, S. P., T. S. A. Costa \& J. A. Silva. 2008. Frutas nativas do Cerrado: caracterização físico-química e fonte potencial de nutrientes, p. 351-381. In: S. M. Sano, S. P. Almeida \& J. F. Ribeiro, (Eds), Cerrado: ecologia e flora. Brasília, DF, Embrapa Informação Tecnológica.

Anderson, W. R. 1979. Floral conservation in neotropical Malpighiaceae. Biotropica 11: 219-223.

Antunes, N. B. \& J. F. Ribeiro. 1999. Aspectos fenológicos de seis espécies vegetais em Matas de Galeria do Distrito Federal. Pesq. Agropec. Bras. 34: 1517-1527.

Ayres, M., D. L. Ayres \& A. A. S. Santos. 2003. BioEstat 3.0: aplicações estatísticas nas áreas das ciências biológicas e médicas. Sociedade Civil Mamirauá, Belém.

Barros, M. A. G. 1998. Sistemas reprodutivos e polinização em espécies de Erythroxylum P. Br. (Erythroxylaceae). Rev. Bras. Bot. 22: 159-166.

Barros, M. A. G. 2002. Floração sincrônica e sistemas reprodutivos em quatro espécies de Kielmeyera Mart. (Guttiferae). Acta Bot. Bras. 16: 113-122.

Batalha, M. A. \& W. Mantovani. 2000. Reproductive phenology patterns of cerrado plant species at the Pé-de-Gigante Reserve (Santa Rita do Passa Quatro, SP, Brazil): a comparison between the herbaceous and woody flora. Rev. Bras. Biol. 60: 129-145.

Bencke, C. S. C. \& P. C. Morellato. 2002. Comparação de dois métodos de avaliação da fenologia de plantas, sua interpretação e representação. Rev. Bras. Bot. 25: 269-275.

Botezelli, L., A. C. Davide \& M. M. Malavasi. 2000. Características dos frutos e sementes de quatro procedências de Dipteryx alata Vogel (Baru). Cerne 6: 9-18.

Brasil. Ministério da Saúde. 2002. Alimentos regionais brasileiros. Brasília, DF.
Cardoso, C. R. P. 2006. Atividade mutagênica e ativadora da resposta imune celular induzidas por Byrsonima crassa Niedenzu e Byrsonima intermedia A. Juss (Malpighiaceae). Dissertação de Mestrado. Universidade Estadual Paulista, Araraquara.

Cavalcante, T. R. M. \& R. V. Naves, E. V. Franceschinelli, R. P. Silva. 2009. Polinização e formação de frutos em araticum. Bragantia 68: 13-21.

Costa, C. B. N., J. A. S. Costa \& M. Ramalho. 2006. Biologia reprodutiva de espécies simpátricas de Malpighiaceae em dunas costeiras da Bahia, Brasil. Rev. Bras. Bot. 29: 103-114.

Cruz, E. D., F. O. Martins \& J. E. U. Carvalho. 2001. Biometria de frutos e germinação de sementes de jatobá-curuba (Hymenaea intermedia Ducke, Leguminosae - Mimosoideae). Rev. Bras. Bot. 24: 161-165.

Cruz, E. D. \& J. E. U. Carvalho. 2002. Biometria de frutos e germinação de sementes de Couratari stellata A.C. Smith (Lecythidaceae). Acta Amazon. 33: 381-388.

Dalponte, J. C. \& E. S. Lima. 1999. Disponibilidade de frutos e a dieta de Lycalopex vetulus (Carnivora - Canidae) em um cerrado de Mato Grosso, Brasil. Rev. Bras. Bot. 22: 325-332.

Falcão, M. A. \& C. R. Clement. 2000. Fenologia e produtividade do ingá-cipó (Inga edulis) na Amazônia Central. Acta Amazon. 30: 173-180.

Farias Neto, J. T., J. U. Carvalho. \& C. H. Muller. 2004. Estimativas de correlação e repetibilidade para caracteres do fruto de bacurizeiro. Ciên. Agrot. 28: 302-307.

Felfili, J. M., M. C. Silva Junior, B. J. Dias \& A. V. Rezende. 1999. Estudo fenológico de Stryphnodendron adstringens (Mart.) Coville no cerrado sensu stricto da Fazenda Água Limpa, no Distrito Federal, Brasil. Rev. Bras. Bot. 22: 83-90.

Felfili, J. M., P. E. Nogueira, M. C. Silva Júnior, B. S. Marimon \& W. B. C. Delitti. 2002. Composição florística e fitossociologia do cerrado sentido restrito no município de Água Boa, MT. Acta Bot. Bras. 16: 103-112. 
Fernandes-Bulhão, C. \& P. S. Figueiredo. 2002. Fenologia de leguminosas arbóreas em uma área de cerrado marginal no nordeste do Maranhão. Rev. Bras. Bot. 25: 361-369.

Figueiredo, M. E., D. C. Michelin, M. Sannomiya, M. A. Silva, L. C. Santos, L. F. R. Almeida, A. R. M. Souza Brito, H. R. N. Salgado \& W. Vilegas. 2005. Avaliação química e da atividade antidiarréica das folhas de Byrsonima cinera DC. (Malpighiaceae). Rev. Bras. Ciênc. Farm. 41: 79-83.

Fournier, L. A. 1974. Un método cuantitativo para la medición de características fenológicas en árboles. Turrialba 24: 422423.

Frankie, G. W, H. G. Baker \& P. A. Opler. 1974. Comparative phenological studies of trees in tropical wet and dry forests in the lowlands of Costa Rica. J. Ecol. 62: 881-913.

Gil, E. S., S. H. P. Serrano, S. H. P. Soares \& K. R. Rezende. 2005. Atividade antioxidante de extrato etanólico e hidroalcoólico de "canjiqueira" (Byrsonima orbignyana). Doseamento de rutina, quercetina, ácido elágico e ácido ascórbico. Rev. Eletr. Farm. 2: 85-88.

Gouveia, G. P. \& J. M. Felfili. 1998. Fenologia de comunidades de Cerrado e de Mata de Galeria no Brasil Central. Rev. Árvore 22: 443-450.

Guimarães, M. M. \& M. S. Silva. 2008. Valor nutricional e características químicas e físicas dos frutos de murici-passa (Byrsonima verbascifolia). Ciên. Tecnol. Alim. 28: 817-821

Gusmão, E., F. A. Vieira \& E. M. Fonseca Júnior. 2006. Biometria de frutos e endocarpos de murici (Byrsonima verbascifolia Rich. ex A. Juss.). Cerne 12: 84-91.

IBGE. Instituto Brasileiro de Geografia e Estatística. 2006. Censo agropecuário 1996. Disponível em: <http:/ / www.sidra.ibge. gov.br/>.

Joly, A. B. 2002. Botânica: introdução à taxonomia vegetal. 2 ed. Companhia Editora Nacional, São Paulo.
Jordano, P. 1995. Angiosperm fleshy fruits and seed dispersers: a comparative analysis of adaptation and constraints in plant-animal interactions. Am. Nat. 145: 163-191.

Klink, C. A. \& R. B Machado. 2005. A Conservação do Cerrado brasileiro. Megadiversidade 1: 147-155.

Lenza, E. \& C. A. Klink. 2006. Comportamento fenológico de espécies lenhosas em um cerrado sentido restrito de Brasília, DF. Rev. Bras. Bot. 29: 627-638.

Lieberman, D. 1982. Seasonality and phenology in a dry tropical forest in Ghana. J. Ecol. 70: 791-806.

Lima, E. D. P. A., C. A. A. Lima, M. L. Aldrigue \& P. J. S. Gondim. 2002. Caracterização física e química dos frutos da umbucajazeira (Spondias spp) em cinco estádios de maturação, da polpa congelada e néctar. Rev. Bras. Frut. 24: 338-343.

Machado, C. G. \& J. Semir. 2006. Fenologia da floração e biologia floral de bromeliáceas ornitófilas de uma área da Mata Atlântica do Sudeste brasileiro. Rev. Bras. Bot. 29: 163-174.

Machado, R. B., M. B. Ramos Neto, P. G. P. Pereira, E. F. Caldas, D. A. Gonçalves, N. S. Santos, K. Tabor \& M. Steininger. 2004. Estimativas de perda da área do Cerrado brasileiro. Relatório técnico não publicado. Conservação Internacional, Brasília, DF.

Mantovani, W. \& F. R. Martins. 1988. Variações fenológicas das espécies do cerrado da Reserva Biológica de Moji-Guaçu, Estado de São Paulo. Rev. Bras. Bot. 11: 101-112.

Marimon, B. S. \& E. S. Lima. 2001. Caracterização fitofisionômica e levantamento florístico preliminar no Pantanal dos Rios Mortes - Araguaia, Cocalinho, Mato Grosso, Brasil. Acta Bot. Bras. 15: 213-229.

Marimon Junior, B. H. \& M. Haridasan. 2005. Comparação da vegetação arbórea e características edáficas de um cerradão e um cerrado sensu stricto em áreas adjacentes sobre solo distrófico no leste de Mato Grosso, Brasil. Acta Bot. Bras. 19: 913-926. 
Martin-Gajardo, I. S. \& L. P. C. Morellato. 2003. Fenologia de espécies Rubiaceae do sub-bosque em floresta Atlântica no sudeste do Brasil. Rev. Bras. Bot. 26: 299309.

Mendanha, D. M., A. P. Kluthcouski, L. P. Felício, W. B. Nunes, \& S. Carvalho. 2008. Efeito modulador da planta medicinal Byrsonima verbascifolia, Rich. Ex. Juss (EBv), contra os danos induzidos pela doxorrubicina em células somáticas de Drosophila melanogaster: SMART/asa. In: $1^{\circ}$ Congresso de Genética do CentroOeste, Brasília, DF. Anais.

Mendes, C. C., F. G. Cruz., J. M. David, I. P. Nascimento \& J. P. David. 1999. Triterpenos esterificados com ácidos graxos e ácidos triterpênicos isolados de Byrsonima microphylla. Juss. Quím. Nova 22: 185-188.

Moraes, P. L. R. \& M. C. Alves. 1997. Biometria de frutos e sementes de Cryptocarya moschata Nees e Endlicheria paniculata (Sprengel) MacBride (Lauraceae). Bol. Mus. Biol. Mello Leitão (N. Sér.) 6: 23-34.

Moraes, P. L. R. \& M. C. Alves. 2002. Biometria de frutos e diásporos de Cryptocarya aschersoniana Mez e Cryptocarya moschata Nees (Lauraceae). Biota Neotropica 2: 1-11.

Morellato, L. P. C. 1995. As estações do ano na floresta. p. 37-41. In: H. F. Leitão Filho \& L. P. C. Morellato (Orgs), Ecologia e preservação de uma floresta tropical urbana: Reserva de Santa Genebra. Campinas, UNICAMP.

Morellato, L. P. C., H. F. Leitão Filho, R. R. Rodrigues \& C. A. Joly. 1990. Estratégias fenológicas de espécies arbóreas em floresta de altitude na Serra do Japi, Jundiaí, São Paulo. Rev. Bras. Biol. 50: 149-162.

Oliveira, P. E. 2008. Fenologia e biologia reprodutiva das espécies de Cerrado, p.273-290. In: S. M. Sano, S. P. Almeida \& J. F. Ribeiro (Eds), Cerrado: ecologia e flora. Brasília, DF, Embrapa Informação Tecnológica.

Oliveira, P. E. A. M. \& F. R. Paula. 2001. Fenologia e biologia reprodutiva de plantas de matas de galeria, p. 303-332. In: J. F. Ribeiro, C. E. L. Fonseca \& J. C. Sousa-Silva (Eds), Cerrado: caracterização e recu- peração de matas de galeria. Planaltina, EMBRAPA-CEPAC.

Oliveira-Filho, A. T. 1984. Estudo fitossociológico de um cerrado da Chapada dos Guimarães, MT: uma análise de gradientes. Dissertação de Mestrado. UNICAMP, Campinas.

Pedron, F. A., J. P. Menezes \& N. L. Menezes. 2004. Parâmetros biométricos de fruto, endocarpo e semente de butiazeiro. Ciên. Rural 34: 585-586.

Penhalber, E. F. \& W. Mantovani. 1997. Floração e chuva de sementes em mata secundária em São Paulo, SP. Rev. Bras. Bot. 20: 205-220.

Pott, A. \& V. J. Pott. 1986. Inventário da flora apícola do pantanal em Mato Grosso do Sul. EMBRAPA-CPAP, Corumbá, 18 p. (Pesquisa em Andamento, 3).

Pott, A., V. J. Pott \& A. A. B. Sobrinho. 2004. Plantas úteis à sobrevivência no pantanal. In: $4^{\circ}$ Simpósio sobre Recursos Naturais e Sócio-Econômicos do Pantanal, Corumbá, MT. Anais.

Ratter, J. A., S. Bridgewater \& J. F. Ribeiro. 2003. Analysis of the floristic composition of the Brazilian cerrado vegetation. III: Comparison of the woody vegetation of 376 areas. Edinb. J. Bot. 60: 57-109.

Rezende, C. M. \& S. R. G. Fraga. 2003. Chemical and aroma determination of the pulp and seeds of murici (Byrsonima crassifolia L.). J. Braz. Chem. Soc. 14: 425-428.

Ribeiro, J. F. \& B. M. T Walter. 1998. Fitofisionomias do Cerrado, p. 89-125. In: S. M. Sano \& S. P. Almeida (Eds), Cerrado: ambiente e flora. Planaltina, EMBRAPACerrados.

Ribeiro, J. F., M. I. Gonçalves, P. E. A. M. Oliveira \& J. T. Melo. 1982. Aspectos fenológicos de espécies nativas do Cerrado. In: $32^{\circ}$ Congresso Nacional de Botânica, Teresina, PI. Anais. p. 181-198.

Sannomiya, M., D. C. Michelin, C. M. Rodrigues, L. C. Santos, H. R. N. Salgado, C. A. Hiruma-Lima, A. R. S. M. Brito \& W. Vilegas. 2005. Byrsonima crassa Niedenzu (IK): antimicrobial activity and chemical study. Rev. Ciênc. Farm. Básica Apl. 26: 71-75. 
Santos, D. L. \& M. Takaki. 2005. Fenologia de Cedrela fissilis Vell. (Meliaceae) na região rural de Itirapina, SP, Brasil. Acta Bot. Bras. 19: 625-632.

Sarmiento, G. 1984. The ecology of neotropical savannas. Harvard University Press, Cambridge.

Silva, F. A. M., E. D. Assad \& B. A. Evangelista. 2008. Caracterização climática do Bioma Cerrado, p. 61-88. In: S. M. Sano, S. P. Almeida \& J. F. Ribeiro, (Eds), Cerrado: ecologia e flora. Brasília, DF, Embrapa Cerrados.

Silva, J. A., D. B. Silva, N. T. V. Junqueira \& R. M. Andrade. 1994. Frutas nativas dos cerrados. EMBRAPA/CPAC, Brasília, DF.

Silva, M. P., R. A. Mauro, G. M. Mourão \& M. Coutinho. 2000. Distribuição e quan- tificação de classes de vegetação do Pantanal através de levantamento aéreo. Rev. Bras. Bot. 23: 143-152.

Toledo, G. L. \& I. I. Ovalle. 1992. Estatística básica. 2. ed. Atlas, São Paulo.

Vicentini, A. \& W.R. Anderson. 1999. Malpighiaceae, p. 505-511. In: J. E. L. S. Ribeiro, M. J. G. Hopkins, A. Vicentini, C. A. Sothers, M. A. S. Costa, J. M. Brito, M. A. D. Souza, L. H. P. Martins, L. G. Lohmann, P. A. C. L. Assunção, E. C. Pereira, C. F Silva, M. R. Mesquita \& L. C. Procópio (Eds), Flora da Reserva Ducke: guia de identificação das plantas vasculares de uma floresta de terra firme na Amazônia Central. v. I. INPA-DFID, Manaus.

Zar, J. H. 1999. Biostatistical analysis. Prentice Hall, New Jersey.

Recebido em 12/IX/2008

Aceito em 31/I/2010 
